\title{
Crystalline structure of annealed polylactic acid and its relation to processing
}

\author{
T. Tábi ${ }^{1}$, I. E. Sajó2, F. Szabó1, A. S. Luyt ${ }^{3}$, J. G. Kovács ${ }^{1 *}$ \\ ${ }^{1}$ Department of Polymer Engineering, Budapest University of Technology and Economics, Múegyetem rkp. 3., H-1111 \\ Budapest, Hungary \\ ${ }^{2}$ Hungarian Academy of Sciences, Chemical Research Center, Department of X-ray Diffraction, Pusztaszeri út 57-59, \\ H-1025 Budapest, Hungary \\ ${ }^{3}$ Department of Chemistry, University of the Free State (Qwaqwa Campus), Private Bag X13, Phuthaditjhaba, 9866, \\ South Africa
}

Received 8 April 2010; accepted in revised form 27 June 2010

\begin{abstract}
This paper focuses on the crystalline structure of injection moulding grade poly(lactic acid) (PLA) and the effect of crystalline structure on the processing. The research is induced by the significant differences in crystallinity of the pure PLA resin, and the injection moulded product, and thus the reprocessing of PLA products. $2 \mathrm{~mm}$ thick PLA sheets were injection moulded and re-crystallized in a conventional oven at $60-140^{\circ} \mathrm{C}$, for $10-60$ minutes to achieve various crystalline contents. The properties of these sheets were investigated by dynamic mechanical analysis (DMA), differential scanning calorimetry (DSC), and wide angle X-ray diffraction (WAXD). In a processing plant the rejected parts are recycled and reused as raw material for further cycles, accordingly the various crystalline content PLA products were reprocessed as a resin, to investigate the processing itself. When PLA products are reprocessed, due to the adherent feature of amorphous PLA processing difficulties may occur. This adherent effect of the amorphous PLA was investigated and characterized.
\end{abstract}

Keywords: biodegradable polymers, polylactic acid, annealing, crystallinity, recycling

\section{Introduction}

In the last few decades interest has turned from the conventional petrol based polymers to biodegradable polymers. This attention is due to the fact that some of these biodegradable polymers can be biobased while the conventional plastics are petrol based. Furthermore, the degradation feature of these biodegradable polymers also carries great advantage in contrast with the low recycled ratio of the mass plastics like polyethylene (PE) or polypropylene (PP). Besides these advantages the products made from biodegradable polymers can be fit in the natural recycling processes [1-4].

Among the bio-based products, most of the research has been made on starch. Starch is a renewable feedstock, which can be found all over the world in significant amounts in agricultural plants like maize, wheat, potato, rice, pea, etc. Based on the experience in the food processing industry, thermoplastic starch (TPS) was developed by disrupting starch granules with the help of heat and shearing action [5-8]. TPS can be further processed with slightly modified equipment like ordinary plastics, however, its drawbacks like low mechanical properties, quick ageing feature, and low water resistant properties made it only adequate for blends mostly in combination with another biodegradable polymer [9-12]. Nowadays the TPS/PCL (polycaprolactone) blend is mostly used for disposable shopping bags. 
Another way of utilizing starch in the field of biopolymers is its fermentation with other biomass products like sugar. In the late 1990's a breakthrough came in the fermentation process of starch and sugar, thus lactic acid was made as a raw material for poly(lactic acid) (PLA). The technology has a reasonable price compared to the synthesis of petrol based plastics, which made PLA to reach wide industrial interest. PLA proved not only to be a fully bio-based and compostable biodegradable polymer, but a biodegradable polymer with excellent mechanical properties, easy processability and reasonable price. Shopping bags, mulch films, cutleries, office utensils, flower pots, yoghurt cans, and toothbrush handles can be made from PLA, but in the near future it can enter into medical applications or it can serve as the material for engineering products [13-15].

Based on the stereoregularity ( $\mathrm{L}$ and $\mathrm{D}$ ) of lactic acid, L, D and D-L type lactides can be used in PLA production. Semi-crystalline PLLA (poly-Llactic acid) or amorphous PDLA (poly-D-lactic acid) can be produced by a ring opening polymerisation of these lactides. For a commercial PLA a blend of a higher amount of L-lactide and a lower amount of D-lactide is used. The ratio of the two lactides influences the mechanical properties, crystallinity and even the degradation characteristics. When semi-crystalline PLA is processed, its crystallinity changes depend on the cooling rate. Typically in injection moulding, due to the high cooling rates, totally amorphous PLA products are produced. In the differential scanning calorimetry (DSC) curve of this amorphous PLA an exotherm can be found, related to the cold crystallization above $T_{g}$, and an endotherm, related to melting. When PLA is recrystallized prior to measurement, the exotherm in the DSC curve is not present $[16,17]$.

During the crystallization of PLLA at high temperatures $\left(>130-140^{\circ} \mathrm{C}\right)$ it is found that the disordered $\alpha^{\prime}$ crystalline form, which can be produced by annealing at lower temperatures, transforms into the ordered $\alpha$ form. The differences between the $\alpha^{\prime}$ and $\alpha$ forms can be observed by wide angle X-ray diffraction (WAXD) spectrometry and DSC analysis [18]. In the WAXD analysis, more intense and new peaks can be found, while in the DSC curves two endothermic peaks appear related to the melting of the $\alpha^{\prime}$ - and $\alpha$ phases. The peak at the lower temperature is related to the melting of the $\alpha^{\prime}$ form and its recrystallization into the $\alpha$ form, while the second peak corresponds to the melting of the $\alpha$ form. The two processes, the melting of the $\alpha^{\prime}$ form and the recrystallization into the $\alpha$ form can be considered as the $\alpha^{\prime}-\alpha$ phase transition. For lower molecular weight PLA, the $\alpha^{\prime}-\alpha$ phase transition occurs at lower temperatures compared to higher molecular weight PLA [18, 19]. Crystallinity also influences the dynamic mechanical analysis (DMA) properties. As it can be seen in the DSC curves, the recrystallization occurs above $T_{g}$ and increases the storage modulus [20].

Recrystallized PLA products also carry a huge advantage compared to amorphous products. This advantage is manifested in the much higher heat deflection temperature (HDT); while amorphous PLA products have an HDT of $50^{\circ} \mathrm{C}$, semi-crystalline PLA products have an HDT of $130^{\circ} \mathrm{C}$. Although PLA can be recrystallized after processing into a product, the products shrink and significant warpage occurs during recrystallization due to the increasing crystallinity. Distortion-free semicrystallized PLA products can only be made during the process using nucleating agents. Talc was found to be an effective nucleating agent, which was observed during DMA analyses [21].

The injection moulding grade PLA with a D-Lactide content of $4 \%$ can be purchased in semi-crystalline form, but when it is processed into a product, or mixed with natural fillers or fibres using melt mixing techniques like extrusion, this PLA becomes amorphous even at very low cooling rates (without the use of nucleating agents). Thus, if it is to be further processed like in the case of PLA based composite pellets or if it is to be reused like in an industrial processing plant where the rejected parts are to be recycled, then because of the change in crystallinity, a totally different material is going to be processed. The changes in crystallinity during processing and its effect on the re-processing have been investigated with injection moulding; furthermore, the properties of various crystalline content injection moulding grade PLA resins were analysed, and the processing difficulties due to crystalline structure were explained. 


\section{Materials, processing and experimental}

Semi crystalline PLA injection moulding grade resin (type Ingeo 3051D from NatureWorks Ltd., USA, with a D-lactide content of $4 \%$ ) was used for the measurements. It was dried at $85^{\circ} \mathrm{C}$ for 6 hours before injection moulding to prevent any degradation due to hydrolysis. $2 \mathrm{~mm}$ thick, $80 \mathrm{~mm}$ by $80 \mathrm{~mm}$ specimens were injection moulded with an Arburg Allrounder 320C 600-250 injection moulding machine equipped with a $\varnothing 35 \mathrm{~mm}$ screw. The injection pressure was 850 bars, while the applied holding pressure was 600 bars. The temperature profile used was $165-175-180-185-190^{\circ} \mathrm{C}$ from the hopper to the nozzle.

In order to produce quality PLA products some precautions were taken. To form a homogenous melt, at least 30 bar of backpressure was necessary with a screw rotational speed of $15 \mathrm{~m} / \mathrm{min}$. In some cases, when the mould opened, the sprue broke, stuck into the stationary mould half and had to be removed manually. To avoid this, a long holding time (20 s) had to be used, not only to compensate for the shrinkage of the part but also for the shrinkage of the sprue, especially to avoid the formation of voids. Furthermore, the part and the sprue had to be adequately stiff to avoid this phenomenon, thus for proper demoulding, long holding and residual cooling times $(30 \mathrm{~s})$ and a low mould temperature $\left(20^{\circ} \mathrm{C}\right)$ had to be used.

The injection moulded samples were totally transparent, indicating their amorphous nature. After injecting the samples, $50 \mathrm{~mm}$ long, $2 \mathrm{~mm}$ by $4 \mathrm{~mm}$ specimens were cut for the DMA measurements, and $2 \mathrm{~mm}$ thick $15 \mathrm{~mm}$ by $15 \mathrm{~mm}$ specimens were cut for the WAXD measurements. The other injection moulded samples were shredded, repelletized, and the amorphous PLA pellets were investigated in two ways: firstly, it was reprocessed in the same way as before to analyse the processing differences; secondly, the pellets were annealed at $80^{\circ} \mathrm{C}$ for only 10 minutes to observe the beginning of the re-crystallization with a scanning electron microscope (SEM) type Jeol JSM6380 LA.

The specimens (for WAXD, DMA and DSC) were placed on a glass plate in a vented oven for annealing at $60-80-100-120-140^{\circ} \mathrm{C}$ for $10-20-30-40-50-$ 60 minutes. The reason for the glass plate support was the low heat deflection temperature of the material. The notation of the samples is as follows: $X / Y$, where $X$ represents the temperature $\left[{ }^{\circ} \mathrm{C}\right]$, and $Y$ represents the time interval [min] of the annealing. The DMA measurements were made with a PerkinElmer Pyris Diamond dynamic mechanical analyser, while the DSC measurements were made with a Perkin-Elmer Pyris 1 differential scanning calorimeter. The crystallinity was calculated from the DSC melting enthalpies, using a melting enthalpy value of $75.57 \mathrm{~J} / \mathrm{g}$ for $100 \%$ crystalline PLLA [22]. The un-annealed specimens were measured at heating rates of $1-2-5-10-15-20^{\circ} \mathrm{C} / \mathrm{min}$, while the annealed specimens were measured at a heating rate of $5^{\circ} \mathrm{C} / \mathrm{min}$. WAXD analysis was done with a Philips model PW 3710 based PW 1050 Bragg-Brentano parafocusing goniometer using $\mathrm{CuK}_{\alpha}$ radiation $(\lambda=0.15418 \mathrm{~nm})$.

Besides the analysis of the crystalline structure of pure PLA, 30 weight $\%$ maize starch (type Meritena 100, from Brenntag Hungária Ltd., Hungary) content PLA was made using a Brabender PlastiCorder PL 2100 twin screw extruder. The processing of the annealed and un-annealed PLA/starch blends was analysed.

\section{Results and discussion}

To analyse the effect of the different crystalline content PLA specimens, they were annealed at different temperatures for different time periods as mentioned before. The transparency of the samples changed from transparent to nearly totally white as the crystallinity increased. This observation was verified by WAXD analysis. The results show that the un-annealed PLA had no crystallinity, but one significant peak appeared at $16.3^{\circ}$ for the specimens annealed at $80^{\circ} \mathrm{C}$. The intensity of the peak increased gradually as a function of annealing time at $80^{\circ} \mathrm{C}$ (Figure 1), and this peak also shifted to $16.6^{\circ}$ for the specimen annealed at $120^{\circ} \mathrm{C}$ for 10 minutes.

Three more peaks appeared at 14.8, 19.0 and at $22.3^{\circ}$ for samples annealed at higher temperatures (Figure 2), which indicate higher crystallinities, but the specimens annealed at 100,120 , and $140^{\circ} \mathrm{C}$ show the same WAXD spectrum independent of annealing time.

These specimens were also analysed by DMA and DSC. At first, the amorphous PLA specimen was examined (Figure 3).

As one can see in the DMA curve, the storage modulus of the amorphous PLA decreases at $T_{g}$, but as a 


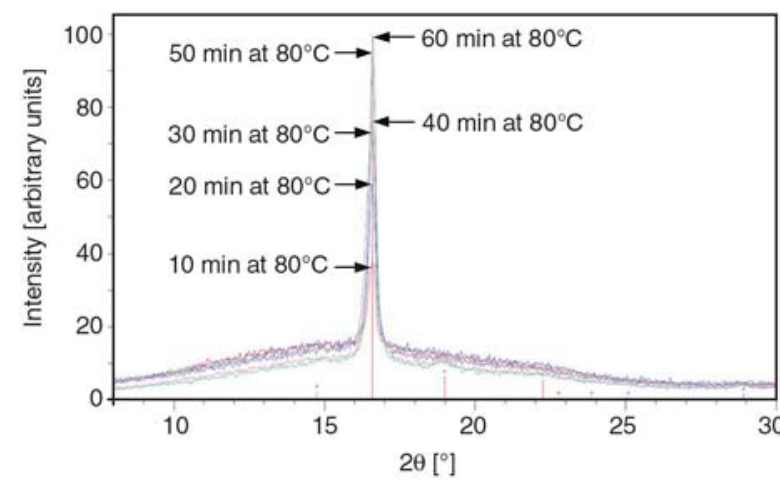

Figure 1. WAXD spectra of PLA annealed at $80^{\circ} \mathrm{C}$ for 10-60 minutes. The intensity of the peak increases as annealing time increases. The arrows point out the peak maxima.

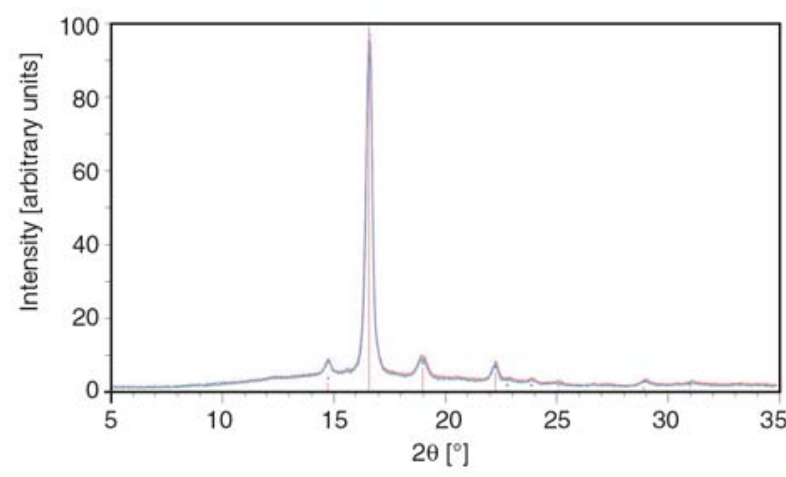

Figure 2. WAXD spectra of PLA annealed at $120^{\circ} \mathrm{C}$ for 10-60 minutes

result of re-crystallization during the measurement the storage modulus returns to that of a semi-crystalline material. In the DSC curve one can observe

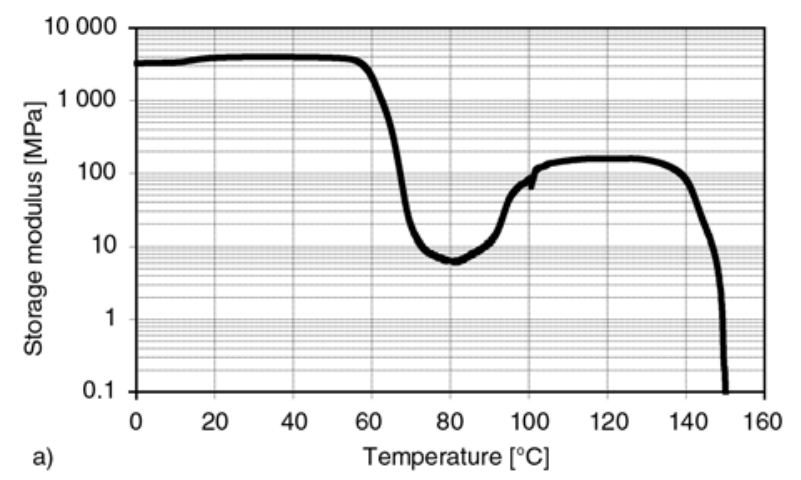

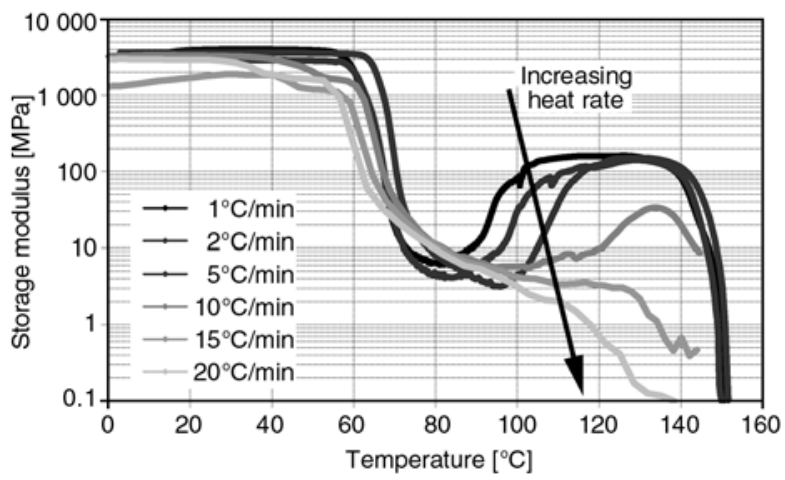

Figure 4. DMA curves of un-annealed PLA captured at 1$2-5-10-15-20^{\circ} \mathrm{C} / \mathrm{min}$ heating rates

the $T_{g}$ at $58^{\circ} \mathrm{C}$, the re-crystallization exotherm between 80 and $105^{\circ} \mathrm{C}$ and the melting endotherm as a double peak between 140 and $160^{\circ} \mathrm{C}$. With the increasing heating rate, the recrystalization during measurement was less significant (Figure 4, Figure 5).

At higher heating rates, the time to develop crystallinity was less, thus the DMA curves tends to the real curve of amorphous PLA. In the DSC curves one can see the decrease in crystallization enthalpies and enthalpies of fusion as the heating rate increases (Table 1).

The crystallization enthalpies and the enthalpies of fusion did not change within experimental error, thus the crystals formed during the cold crystallization at lower temperatures melted at $150^{\circ} \mathrm{C}$. The crystallization peak has also shifted to higher tem-

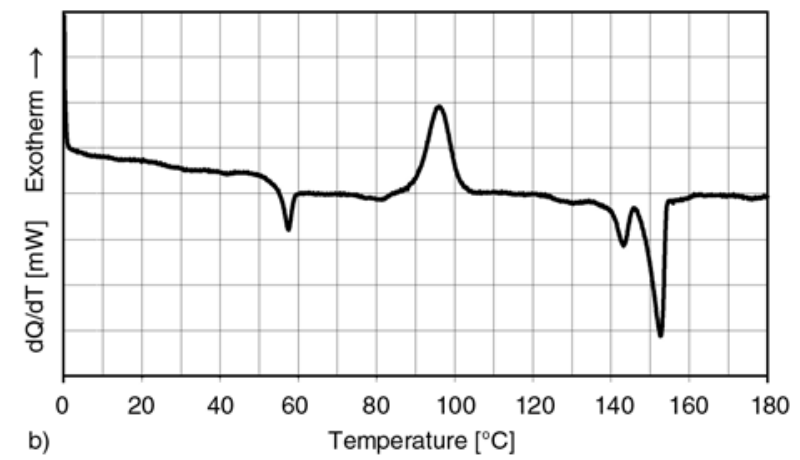

Figure 3. (a) DMA and (b) DSC curves of un-annealed, amorphous PLA captured at a $1^{\circ} \mathrm{C} / \mathrm{min}$ heating rate

Table 1. Crystallization enthalpies and enthalpies of fusion of the unannealed specimens

\begin{tabular}{|c|c|c|c|c|}
\hline $\begin{array}{c}\text { Heat rate } \\
{\left[{ }^{\circ} \mathbf{C} / \mathbf{m i n}\right]}\end{array}$ & $\begin{array}{c}\text { Crystallization } \\
\text { peak }\left[{ }^{\circ} \mathbf{C}\right]\end{array}$ & $\begin{array}{c}\text { Crystallization } \\
\text { enthalpy }[\mathbf{J} / \mathbf{g}]\end{array}$ & $\begin{array}{c}\text { Melting } \\
\text { peak }\left[{ }^{\circ} \mathbf{C}\right]\end{array}$ & $\begin{array}{c}\text { Enthalpy } \\
\text { of fusion }[\mathbf{J} / \mathbf{g}]\end{array}$ \\
\hline 2 & 96.1 & -25.8 & 152.6 & 25.3 \\
\hline 5 & 107.7 & -29.9 & 152.6 & 27.5 \\
\hline 10 & 117.8 & -22.4 & 149.2 & 22.7 \\
\hline 15 & 126.1 & -11.4 & 151.9 & 5.5 \\
\hline 20 & 130.7 & -4.8 & 154.4 & 5.5 \\
\hline
\end{tabular}



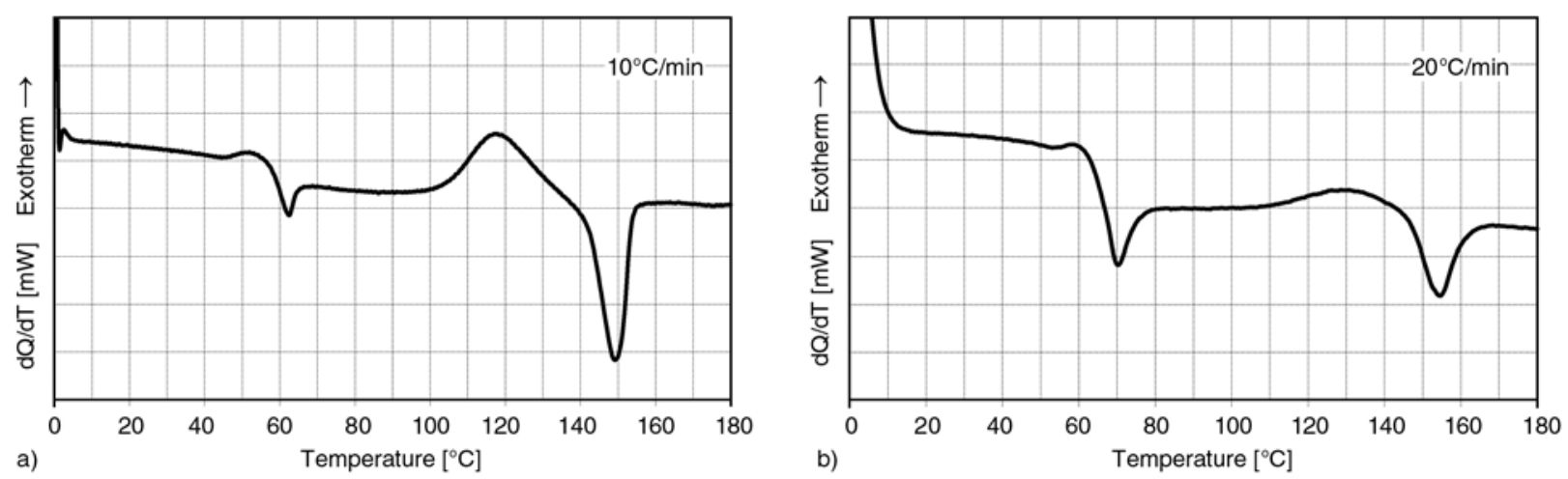

Figure 5. DSC curves of un-annealed PLA captured at (a) 10 and (b) $20^{\circ} \mathrm{C} / \mathrm{min}$ heating rates

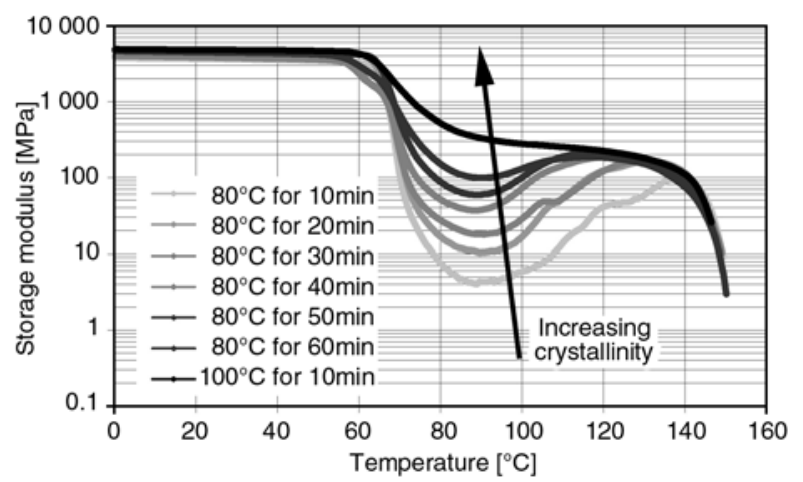

Figure 6. DMA curves of annealed PLA. The annealing temperatures and time intervals from the bottom curve to the top are: $80 / 10,80 / 20,80 / 30,80 / 40$, $80 / 50,80 / 60,100 / 10$

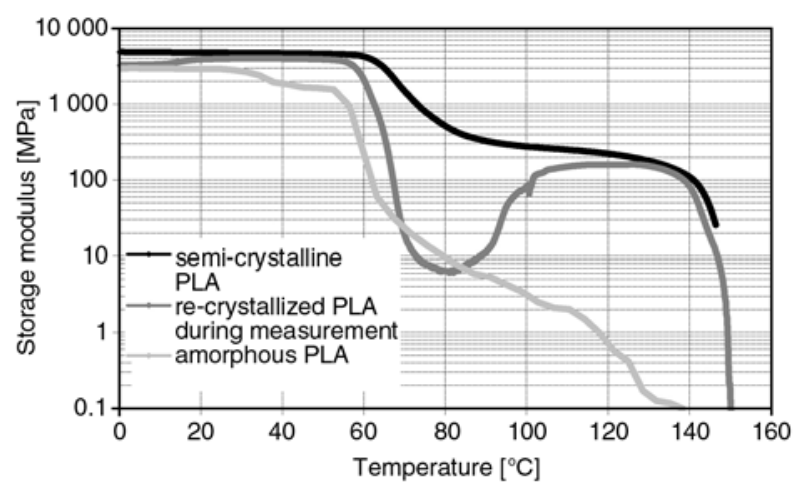

Figure 7. The DMA curve of amorphous, semi crystalline, and re crystallized PLA peratures. For the annealed specimens, the loss in storage modulus decreased with increasing crystalline content (Figure 6).

It can be seen that during the measurement the unannealed specimens fully re-crystallized, since the storage moduli returned to those of the specimen with the highest possible crystallinity around 120 $140^{\circ} \mathrm{C}$. The higher the crystallinity, the lower the storage modulus drop observed at the glass transition. Figure 7 summarizes the DMA curves for amorphous PLA, semi-crystalline PLA, and PLA re-crystallizing during measurement.

In the DSC curves the intensity of the exothermic peak observably decreases with increasing PLA crystallinity (Figure 8).

The enthalpy of fusion does not seem to change significantly after the different heat treatments (Table 2.), but from the differences in cold crystallization it is clear that the samples reached their maximum crystallinity after only 10 minutes at 100 and $120^{\circ} \mathrm{C}$. It is further interesting that the double melting peak, indicative of the melting of both the $\alpha^{\prime}$ - and $\alpha$ crystalline phases, changed to a single melting peak typical of the $\alpha$ crystalline phase.

The supplier of PLA Ingeo 3051D has published a know-how about crystallizing and drying of PLA [23]. The adherent feature of the amorphous PLA and the solution is well discussed, and warnings

Table 2. Crystallinity values, crystallization enthalpies and enthalpies of fusion of the annealed specimens

\begin{tabular}{|c|c|c|c|c|c|}
\hline $\begin{array}{l}\text { Annealing time } \\
\text { and temperature }\end{array}$ & $\begin{array}{c}\text { Crystallization } \\
\text { peak }\left[{ }^{\circ} \mathbf{C}\right]\end{array}$ & $\begin{array}{l}\text { Crystallization } \\
\text { enthalpy }[\mathrm{J} / \mathrm{g}]\end{array}$ & $\begin{array}{c}\text { Melting } \\
\text { peak }\left[{ }^{\circ} \mathrm{C}\right]\end{array}$ & $\begin{array}{c}\text { Enthalpy } \\
\text { of fusion }[\mathrm{J} / \mathrm{g}]\end{array}$ & $\begin{array}{c}\text { Crystallinity } \\
{[\%]}\end{array}$ \\
\hline $80^{\circ} \mathrm{C}, 10 \mathrm{~min}$ & 105.4 & -18.4 & 150.8 & 20.9 & 3.3 \\
\hline $80^{\circ} \mathrm{C}, 20 \mathrm{~min}$ & 100.9 & -16.3 & 152.1 & 21.4 & 6.7 \\
\hline $80^{\circ} \mathrm{C}, 30 \mathrm{~min}$ & 99.4 & -17.8 & 151.9 & 21.8 & 5.3 \\
\hline $80^{\circ} \mathrm{C}, 40 \mathrm{~min}$ & 95.4 & -13.2 & 152.1 & 23.0 & 13.0 \\
\hline $80^{\circ} \mathrm{C}, 50 \mathrm{~min}$ & 91.1 & -11.4 & 150.9 & 24.5 & 17.3 \\
\hline $80^{\circ} \mathrm{C}, 60 \mathrm{~min}$ & 96.4 & -7.5 & 150.4 & 23.4 & 21.0 \\
\hline $100^{\circ} \mathrm{C}, 10 \mathrm{~min}$ & none & none & 151.4 & 25.8 & 34.1 \\
\hline $120^{\circ} \mathrm{C}, 10 \mathrm{~min}$ & none & none & 151.6 & 29.0 & 38.4 \\
\hline
\end{tabular}



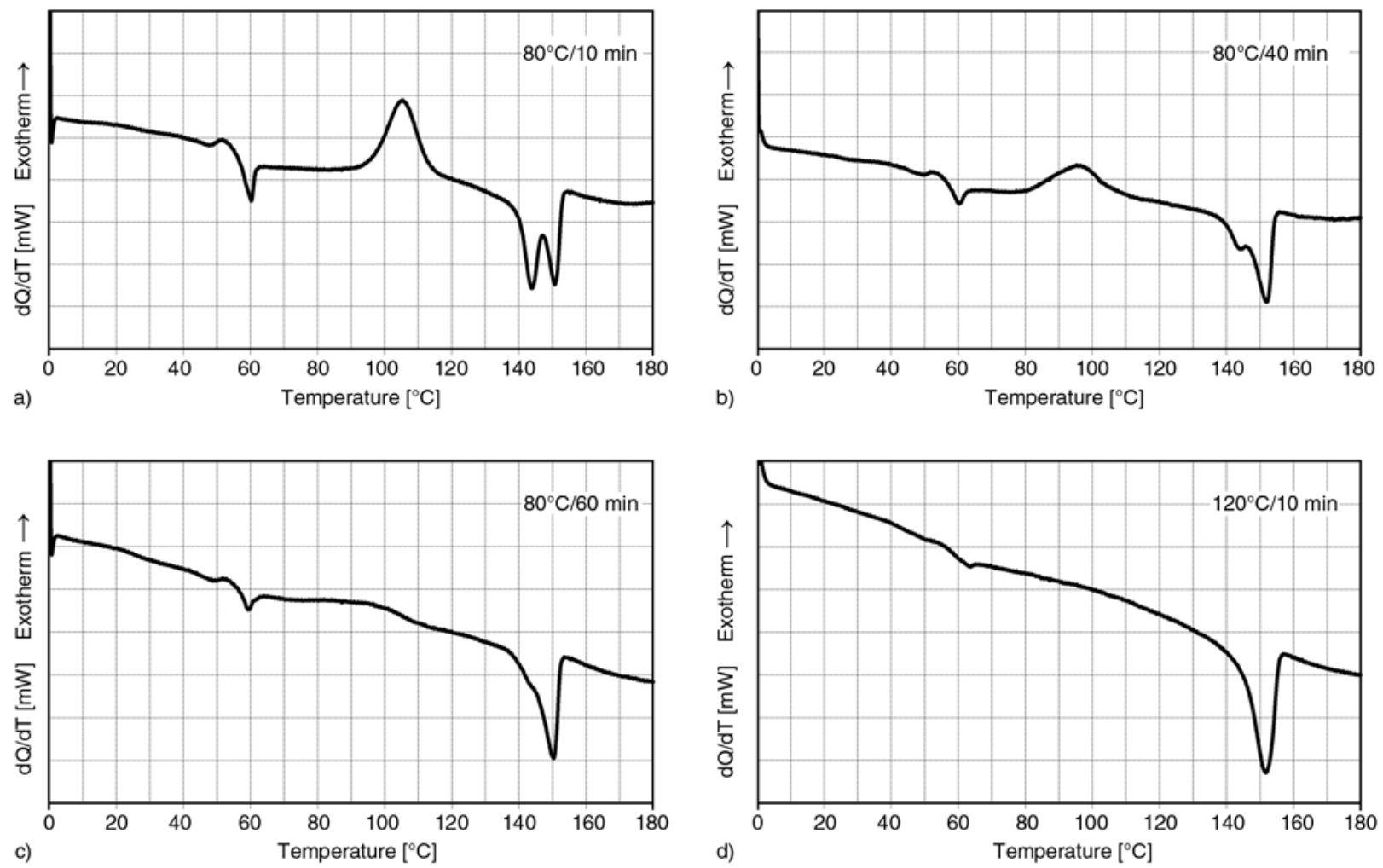

Figure 8. DSC curves of PLA annealed at $80^{\circ} \mathrm{C}$ for (a) 10, (b) 40, (c) 60 minutes and (d) at $120^{\circ} \mathrm{C}$ for 10 minutes

about pneumatic material transportation from driers to processing equipment are mentioned. Amorphous PLA was injection moulded to investigate the effect of recycled PLA on the processing, but it was found that from cycle to cycle more and more amorphous PLA pellets stuck to the surface of the screw and rotated together with the screw. The pellets stuck on the screw even at the feed zone, where the material should only be transported to the compression zone, but not melted (Figure 9).

As more and more pellets stuck to the screw, more and more torque was necessary to plasticize the

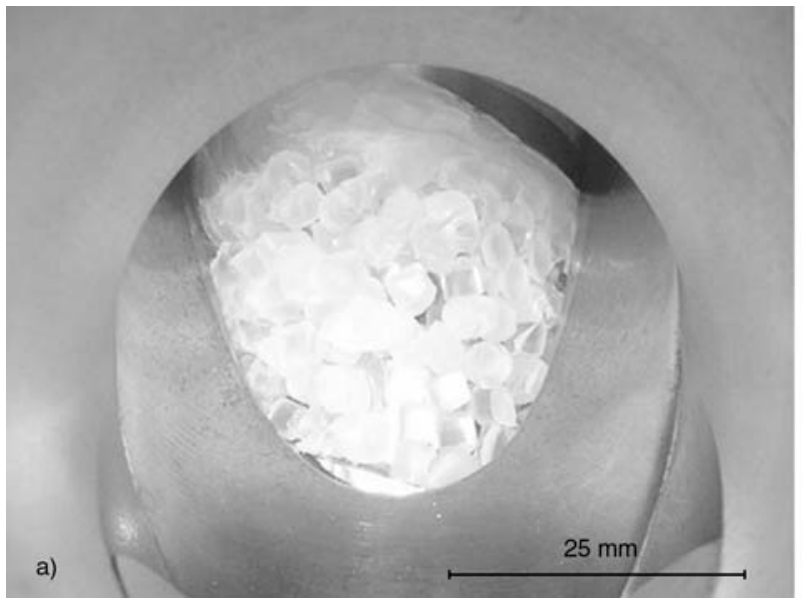

material; finally it reached a value which could destabilize the injection moulding process. This phenomenon prevented further processing of the material until the barrel is cleaned. This effect was characterized by the number of 'problem free' processes before the needed cleaning procedure. For amorphous PLA, and for the used injection moulding machine and parameters, the number of problem free processes was around 10 cycles. To further analyse the adherent effect with SEM, amorphous pellets were heated at $80^{\circ} \mathrm{C}$ for $10 \mathrm{~min}$ utes in a conventional oven (Figure 10).

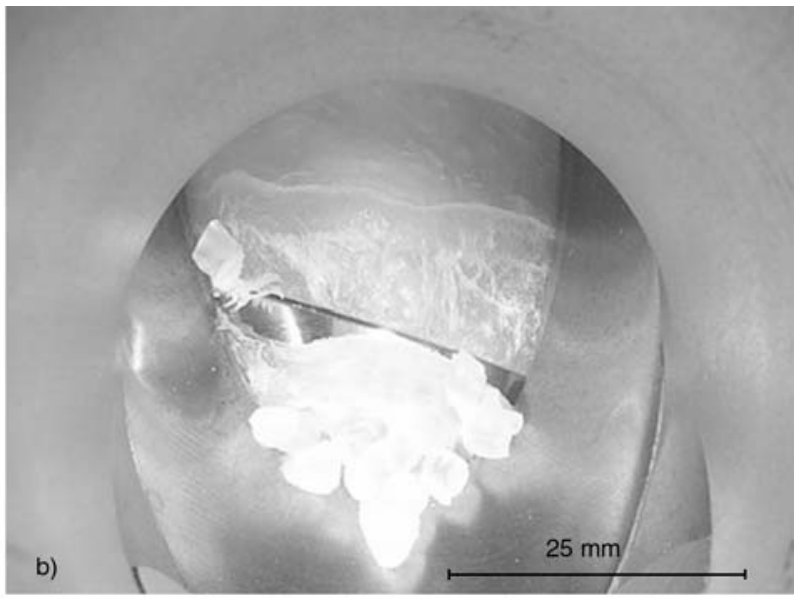

Figure 9. The amorphous PLA pellets stuck on the surface of the screw at the (a) beginning and at the (b) end of the feeding zone 


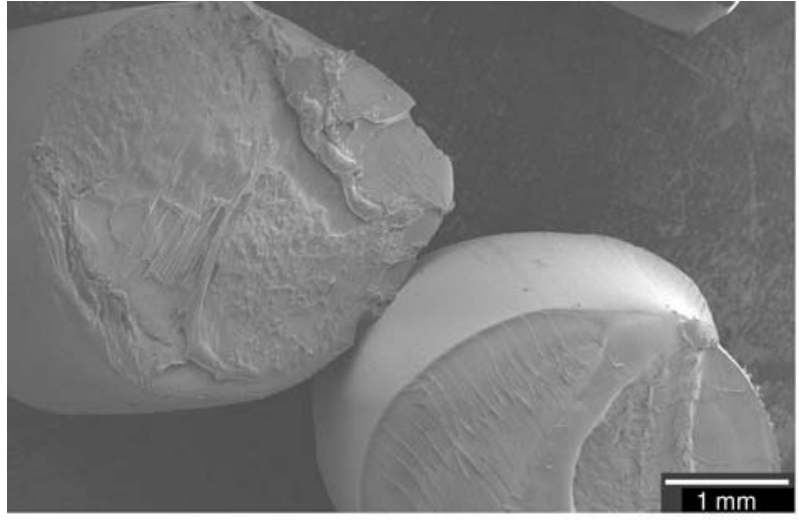

a)

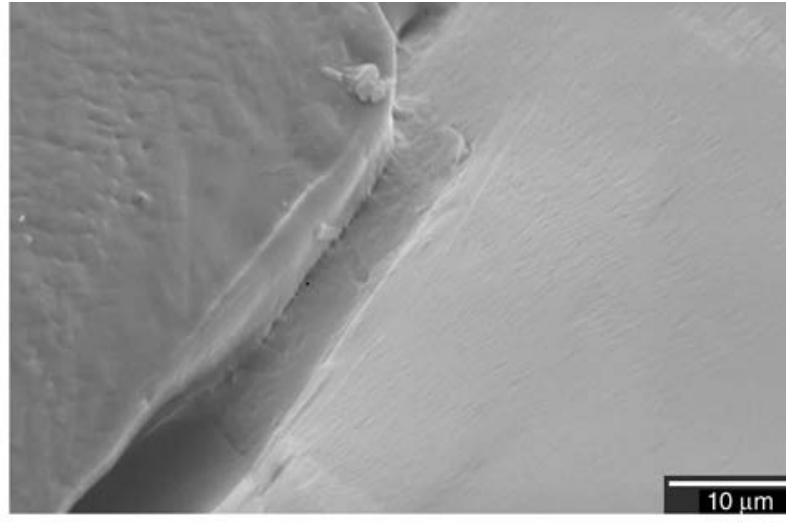

b)

Figure 10. Welded surface of pellets at $80^{\circ} \mathrm{C}$, with a magnification of (a) 20 and (b) 2000

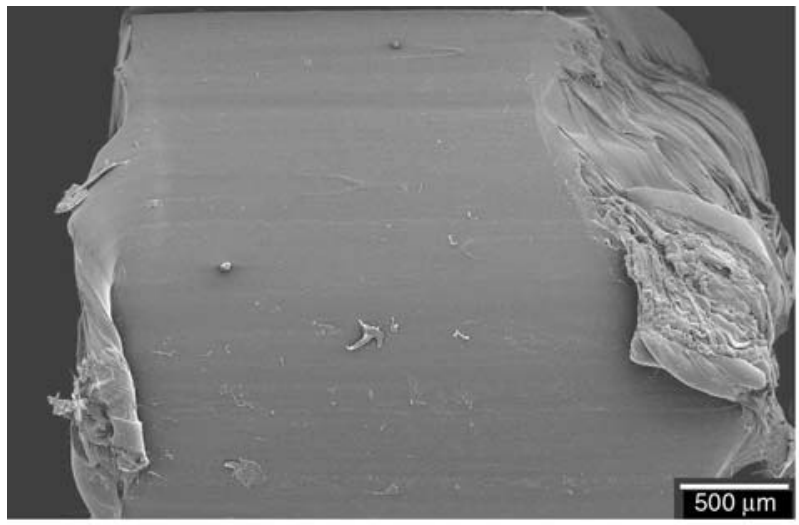

a)

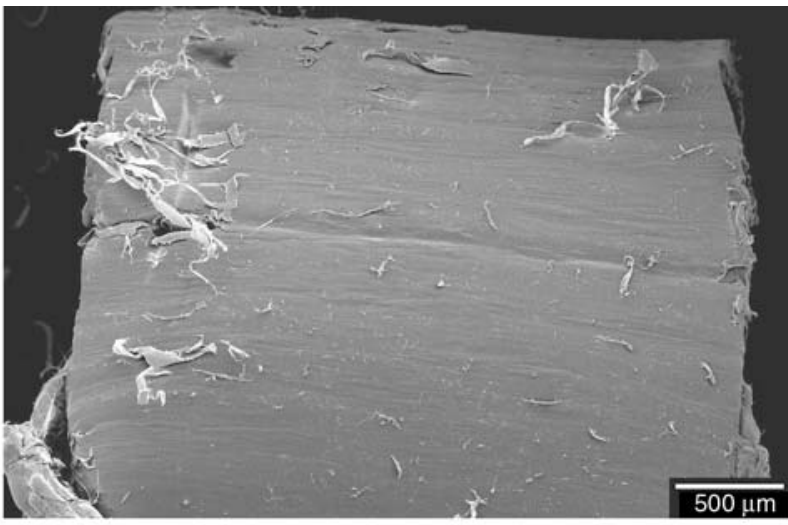

b)

Figure 11. (a) Unannealed and (b) annealed pellet with peeled-off ribbons

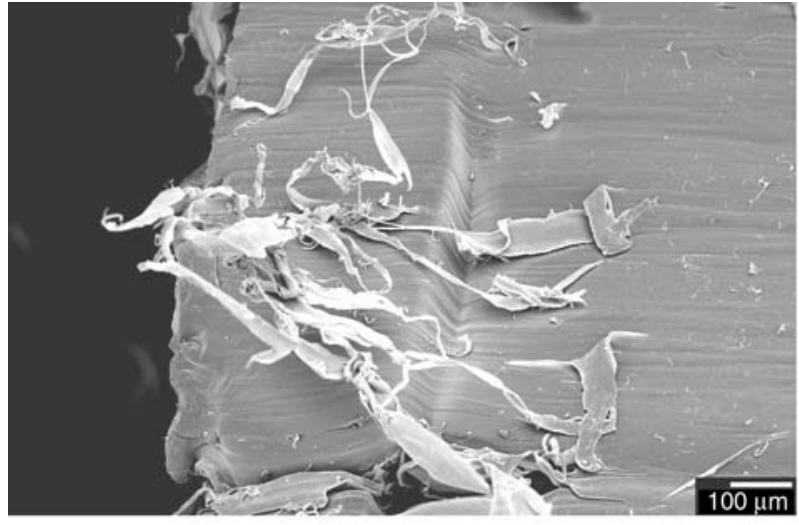

a)

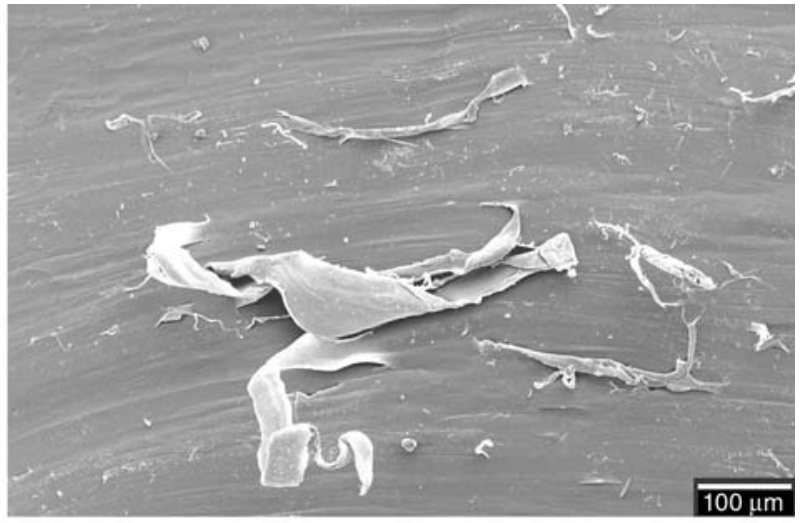

b)

Figure 12. Peeled-off ribbons on the surface of PLA pellet, with a magnification of (a) 100 and (b) 150

As the SEM pictures showed, the pellets locally welded together, and a weld line between the pellets developed even at this low temperature. It can also be observed that for the pellets annealed at $120^{\circ} \mathrm{C}$ for 10 minutes, ribbon-like PLA formations peeled off the surface of the pellet, suggesting local melting of the pellets during crystallization (Figure 11, Figure 12).
This 'melting' is probably caused by the significant exothermic cold crystallization heat and the low heat transfer capabilities of PLA, and can be related to the softening of the amorphous phase only. During cold crystallization the exothermic heat is transported to the surface of the pellet, where due to the low heat transfer capabilities of PLA the accumulated exothermic heat causes local softening of the 

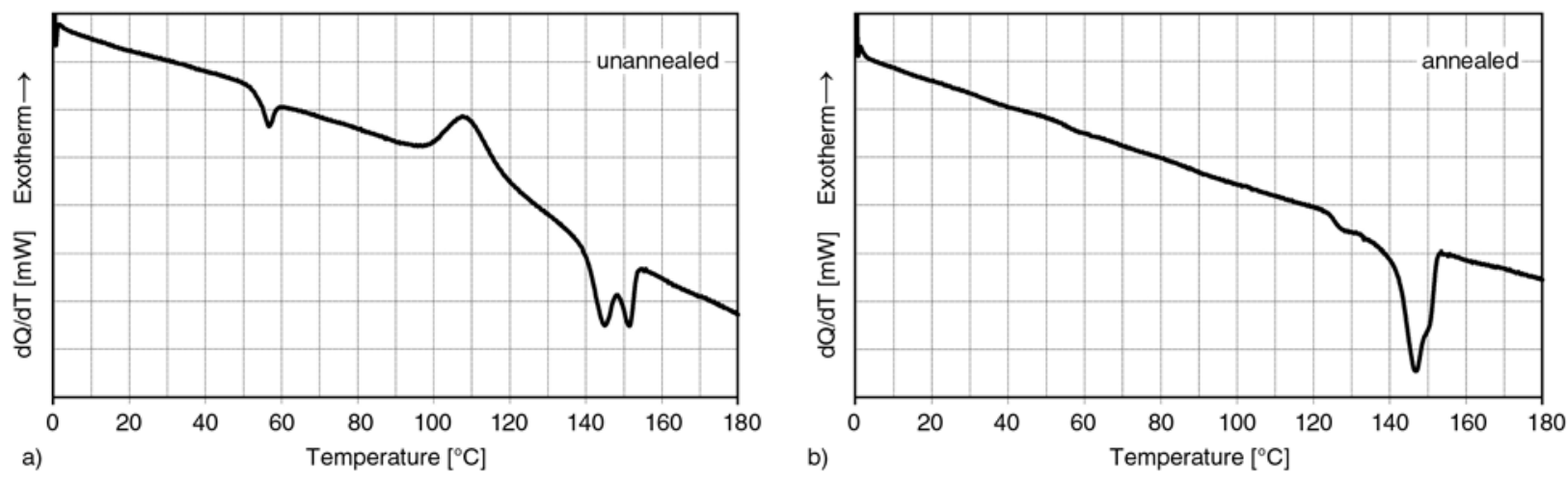

Figure 13. DSC curves of (a) annealed and (b) unannealed PLA/starch blends

amorphous phase. With the continuation of cold crystallization, the crystallinity increases which already retards the macro Brownian movement. Accordingly, the injection moulding difficulties could be totally overcome by the annealing of the amorphous pellets in a vented oven prior to injection moulding, because with higher crystallinity the re-crystallization phenomenon becomes negligibly small or disappears. The pellets will also stick together during the annealing process, but with low mechanical action they can be separated easily. With proper crystallization, the processing of recrystallized PLA pellets was as easy as the processing of original (virgin) pellets; there were no processing problems within the investigated 100 injection cycles.

Although many authors made PLA based composites and further processed the pellets into injection moulded products, only a few reported the adherent effect, and even fewer reported that annealing was done before injection moulding. To analyse the effect of annealing on PLA based blends, 30 weight $\%$ starch content PLA was made using a twin screw extruder. The differences between the annealed (at $120^{\circ} \mathrm{C}$ for 60 minutes) and un-annealed blends can be seen in the DSC curves (Figure 13).

Here it can also be seen that after annealing the exothermic peak responsible for the adhering feature of the amorphous PLA - and thus causing unstable injection moulding technology - disappeared. No adherent effect was found with annealing of the PLA/starch blend, while the un-annealed pellets led again to processing difficulties. The injection moulding of the annealed pellets of the PLA/starch blend was found to be stable.

\section{Conclusions}

The crystalline structure of injection moulding grade polylactic acid (PLA) was analysed by wide angle X-ray diffraction (WAXD) spectrometry, dynamic mechanical analysis (DMA), differential scanning calorimetry (DSC), and the effect of the crystalline structure on the processing with injection moulding was analysed. The research is induced by the significant differences in crystallinity of the pure PLA resin, and the injection moulded product, and thus the reprocessing of PLA products. Different temperatures $\left(60-140^{\circ} \mathrm{C}\right)$ and time intervals (10-60 minutes) were used to investigate the crystallization of injection moulded amorphous PLA specimens in a vented oven. The WAXD results show that in an annealing temperature range of $100-140^{\circ} \mathrm{C}, 10$ minutes were enough to achieve as high crystallinity as possible for injection moulding grade PLA (crystalline content around $40 \%$ ). The DMA properties show that the amorphous specimens re-crystallized during measurement, which gave rise to an increase in the storage modulus above $T_{g}$. At a high heating rate it was possible to measure the DMA curve of the amorphous PLA, thus the differences in DMA curves of the amorphous and semi-crystalline PLA could be studied. The DSC results showed a significant exothermic peak in the temperature range of 80 $140^{\circ} \mathrm{C}$ which is related to cold crystallization. The exothermic peak decreased with increasing crystallinity, thus no exothermic peak could be observed for the fully annealed specimens (specimens with around $40 \%$ crystalline content).

Amorphous PLA was injection moulded to investigate the effect of recycled PLA on the processing, 
but due to the adherent feature of the amorphous PLA, pellets stuck to the screw already in the feeding zone, where the material should be only transported but not melted. This phenomenon destabilized the injection moulding process, preventing further processing after 10 injection cycles. It was observed by scanning electron microscopy (SEM) that the pellets welded together locally, and that ribbon-like formations peeled off the surface of the pellets. This suggests that during processing, due to the significant crystallization exotermic heat accumulated at the surface of the pellets, and due to the low heat transfer capability of the material, the amorphous phase of the pellets softens locally and causes the adherent effect that destabilizes the injection moulding processing. These injection moulding difficulties can be totally overcome by re-crystallization of the amorphous material prior to the injection. In this case, within the investigated 100 injection cycles, the processing was easy and problem-free, like the processing of semi-crystalline PLA. It was also found that annealing is also effective in eliminating processing difficulties when processing PLA based, starch filled materials.

\section{Acknowledgements}

This paper was supported by the János Bólyai Research Scholarship of the Hungarian Academy of Sciences and the Hungarian-French (TéT FR-5/2007) Intergovernmental Science and Technology Cooperation Programme. The authors would like to thank Arburg Hungária Kft. for the injection moulding machine, Wittmann Robottechnika Kft. for the W711 robot and the mould temperature control unit, and Lenzkes $\mathrm{GmbH}$ for the clamping tool system.

\section{References}

[1] Avérous L.: Biodegradable multiphase systems based on plasticized starch: A review. Polymer Reviews, 44, 231-274 (2004). DOI: $10.1081 / \mathrm{MC}-200029326$

[2] Ren X.: Biodegradable plastics: A solution or a challenge? Journal of Cleaner Production, 11, 27-40 (2003).

DOI: $10.1016 / \mathrm{S} 0959-6526(02) 00020-3$

[3] Zhang M. Q.: Polymeric materials from natural resources- Emerging as the times require. Express Polymer Letters, 1, 406 (2007).

DOI: 10.3144/expresspolymlett.2007.57
[4] Siracusa V., Rocculi P., Romani S., Dalla Rosa M.: Biodegradable polymers for food packaging: A review. Trends in Food Science and Technology, 19, 634-643 (2008).

DOI: $10.1016 /$ j.tifs.2008.07.003

[5] Czigány T., Romhány G., Kovács J. G.: Starch for injection moulding purposes. in 'Engineering biopolymers: Homopolymers, blends, and composites' (eds.: Fakirov S., Bhattacharyya D.) Hanser Publisher, Munich, Vol 1, 81-108 (2006).

[6] Tábi T., Kovács J. G.: Examination of injection moulded thermoplastic maize starch. Express Polymer Letters, 1, 804-809 (2007). DOI: 10.3144/expresspolymlett.2007.111

[7] Gáspár M., Benkô Zs., Dogossy G., Réczey K., Czigány T.: Reducing water absorption in compostable starch-based plastics. Polymer Degradation and Stability, 90, 563-569 (2005).

DOI: 10.1016/j.polymdegradstab.2005.03.012

[8] Stepto R. F. T.: The processing of starch as a thermoplastic. Macromolecular Symposia, 201, 203-212 (2003).

DOI: $\underline{10.1002 / \operatorname{masy} .200351123}$

[9] Averous L., Moro L., Dole P., Fringant C.: Properties of thermoplastic blends: Starch-polycaprolactone. Polymer, 41, 4157-4167 (2000). DOI: $\underline{10.1016 / \mathrm{S} 0032-3861(99) 00636-9}$

[10] Avérous L., Fringant C.: Association between plasticized starch and polyesters: Processing and performances of injected biodegradable systems. Polymer Engineering and Science, 41, 727-734 (2001). DOI: $10.1002 /$ pen. 10768

[11] Avérous L., Fauconnier N., Moro L., Fringant C.: Blends of thermoplastic starch and polyesteramide: Processing and properties. Journal of Applied Polymer Science, 76, 1117-1128 (2000).

DOI: 10.1002/(SICI)1097-4628(20000516)76:7<1117 $\because$ AID-APP16>3.0.CO;2-W

[12] Schwach E., Avérous L.: Starch-based biodegradable blends: Morphology and interface properties. Polymer International, 53, 2115-2124 (2004). DOI: $10.1002 /$ pi.1636

[13] Mohanty A. K., Misra M., Hinrichsen G.: Biofibres, biodegradable polymers and biocomposites: An overview. Macromolecular Materials and Engineering, 276-277, 1-24 (2000).

DOI: $10.1002 /($ SICI)1439-2054(20000301)276:1<1 $\because$ AID-MAME1>3.0.CO;2-W

[14] Yu L., Dean K., Li L.: Polymer blends and composites from renewable resources. Progress in Polymer Science, 31, 576-602 (2006).

DOI: 10.1016/j.progpolymsci.2006.03.002

[15] Vilpoux O., Avérous L.: Starch-based plastics. in 'Technology, use and potentialities of Latin American starchy tubers' (eds.: Cereda M. P., Vilpoux O.) NGO Raízes and Cargill Foundation, São Paolo, Brasil, Vol 3, 521-553 (2004). 
[16] Lim L-T., Auras R., Rubino M.: Processing technologies for poly(lactic acid). Progress in Polymer Science, 33, 820-852 (2008).

DOI: 10.1016/j.progpolymsci.2008.05.004

[17] Pyda M., Bopp R. C., Wunderlich B.: Heat capacity of poly(lactic acid). Journal of Chemical Thermodynamics, 36, 731-742 (2004). DOI: $10.1016 /$ j.jct.2004.05.003

[18] Pan P., Zhu B., Kai W., Dong T., Inoue Y.: Polymorphic transition in disordered poly(L-lactide) crystals induced by annealing at elevated temperatures. Macromolecules, 41, 4296-4304 (2008).

DOI: $10.1021 / \mathrm{ma} 800343 \mathrm{~g}$

[19] Pan P., Kai W., Zhu B., Dong T., Inoue Y.: Polymorphous crystallization and multiple melting behavior of poly(L-lactide): Molecular weight dependence. Macromolecules, 40, 6898-6905 (2007).

DOI: $\underline{10.1021 / \mathrm{ma} 071258 \mathrm{~d}}$
[20] Martin O., Avérous L.: Poly(lactic acid): Plasticization and properties of biodegradable multiphase systems. Polymer, 42, 6209-6219 (2001).

DOI: $10.1016 / \mathrm{S} 0032-3861(01) 00086-6$

[21] Li H., Huneault M. A.: Effect of nucleation and plasticization on the crystallization of poly(lactic acid). Polymer, 48, 6855-6866 (2007). DOI: $10.1016 /$ j.polymer.2007.09.020

[22] Kantoglu Ö., Güven O.: Radiation induced crystallinity damage in poly(L-lactic acid). Nuclear Instruments and Methods in Physics Research Section B: Beam Interactions with Materials and Atoms, 197, 259-264 (2002).

DOI: $\underline{10.1016 / \mathrm{S} 0168-583 X(02) 01473-8}$

[23] NatureWorks: Crystallizing and drying of PLA. http://www.natureworksllc.com (2010). 